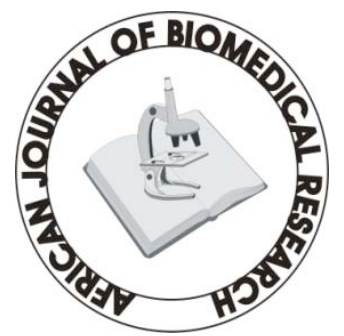

Full-text available at http://www.ajbrui.com http://www.bioline.br/md http://www.ajol.com

Received:

December 2007

Accepted (Revised): May 2008

Published

September 2008
Full Length Research Article

\section{Validity of Self Completed Health Questionnaire among Oral Surgery Patients in Capitol Dental}

\author{
${ }^{* 1}$ Davidson Lawoyin, ${ }^{*}$ Rene McCoy-Collins, ${ }^{* *}$ Temidayo \\ Obayomi, ${ }^{* *}$ Errol Reid, "**Frances Sam, ${ }^{* *}$ Adrea Bonnick, \\ ${ }^{* * *}$ Robert Jones and ${ }^{* * * *}$ Jonathan Lawoyin \\ *Capitol Dental Washington D.C \\ **Department of Oral \& Maxillofacial Surgery, Howard University, USA \\ ***Department of Oral \& Maxillofacial Pathology, University of Ibadan
}

\begin{abstract}
Objective of this study is to determine the degree of validity of self completed health questionnaire among oral surgery patient at the Capitol Dental when compared with a structured oral interview. A prospective random selection method was applied using a standardized questionnaire. The cohorts are patients attending Capital Dental Clinic ambulatory emergency care department of the Washington D.C. Public Health Institution. One hundred and forty (140) patients who presented for the first time at the Dental Clinic on emergency basis were involved. Patients between ages 50-60 are the most predominant at $31.4 \%$, followed by ages $40-50$ at $28.6 \%$. Ethnically, the African-American population are by far the most represented at $84.3 \% .24$ no responses or $7.1 \%$ of the 140 patients under study missed at least one question each in the self completed health questionnaire. The medial history that reflect the highest disparity percentage when the two modalities of questionnaire were compared is substance abuse 7.8\%, followed by HTN $5.7 \%$, HIV 3.6\%, and Cardiovascular diseases at 2.8\%. It was concluded that self completed health questionnaire should be formally tested before use and be sensitive to differences in social background and culture. One method can not be used exclusively.
\end{abstract}

(Afr. J. Biomed. Res. 11: 275 - 279)

Key word: Oral surgery, questionnaire, Washington D.C, patients

${ }^{1}$ Address for Correspondence: Howard University College of Dentistry, Department of Oral \& Maxillofacial Surgery, 600 “W” Street N.W, Washington D.C 20059. E.mail: dlawoyin@howard.edu

Abstracted by:

African Index Medicus (WHO), CAB Abstracts, Index Copernicus, Global Health Abstracts, Asian Science Index, Index Veterinarius, Bioline International, African Journals online 


\section{INTRODUCTION}

The ability of self-completed questionnaire to yield accurate medical histories has been in question for some time. Obtaining a reliable medical history from patients before dental treatment to detect underlying medical problems is extremely invaluable. Brady and Martinoff (1980) and 'Scully and Boyle (1983) concluded in their study that it cannot be assumed that dental patients provide valid health history information on the written self-administered health questionnaire. There are many arguments for adequate and current medical history among dental patient, the most important of these is the avoidance of serious complication. Safe delivery of dental treatment particularly when it is fairly invasive as those commonly seen in Oral Surgery clinics depends largely on accurate medical history. It is the responsibility of the treating dentist to be knowledgeable in identifying which medical problems can put the patient at risk (Absi, 1987; McCarthy 1987). This study was prompted by the desire to know where the population we serve fall in terms of the validity of the history they offer us.

\section{MATERIALS AND METHODS}

Capitol Dental is located in Washington D.C and operates along with other medical specialties in the government sponsored Ambulatory Care Center located in South Eastern part of the city. It caters largely to residents of the city who are uninsured by providing them with a community based primary care through an integrated and culturally appropriate system. The clinic serves as a referral center for about seven neighborhood dental clinics. This study did a random selection of 140 patients among those who were referred for the first time to oral surgery. The selection was made between January 2007- March 2007. The patients in question were informed that they should complete the health history as accurately as possible to enable the surgeon give them the best treatment. The patients were then made to complete a health questionnaire unassisted, with the exception of the Spanish speaking ones who got translations from a Spanish speaking member of staff. Patients were subsequently subjected to a detailed verbal interview by the oral surgeon. Eleven health history that are deemed to be medical risk-related or relevant to surgical procedure were the first to be asked and recorded separately. Following the completion of the oral interview the responses from the self completed form is compared with that of the structured oral interview. The results to these eleven questions alone were then separated from the rest of the questionnaires and analyzed for age, gender, cause of disparity in responses, and ethnicity.

\section{RESULTS}

Twenty-four out of the one hundred and forty patients in this study gave no response to at least one question in the self-completed health questionnaire category.

\section{Age Distribution:}

The mean age is 45.9 years and the most predominant age group for all the patients is between 50-60 years (31.4\%).Figure 1. Between the sexes the same age group is predominant showing (42.2\%) among the males and (30.3\%) among the females. Figure2.

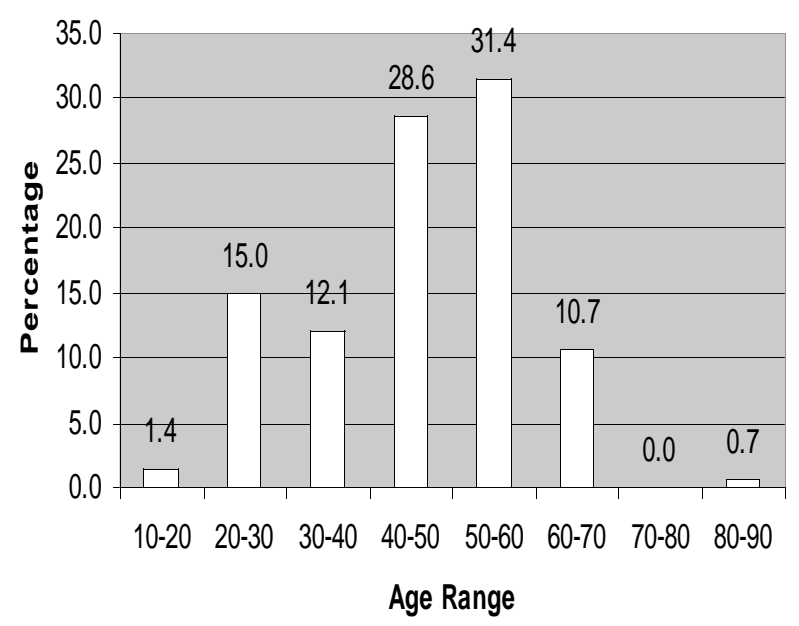

Fig. 1

Age distribution among male and female 
African Journal of Biomedical Research 2008 (Vol. 11) / Lawoyin, Mc-Coy-Collins, Obayomi et al

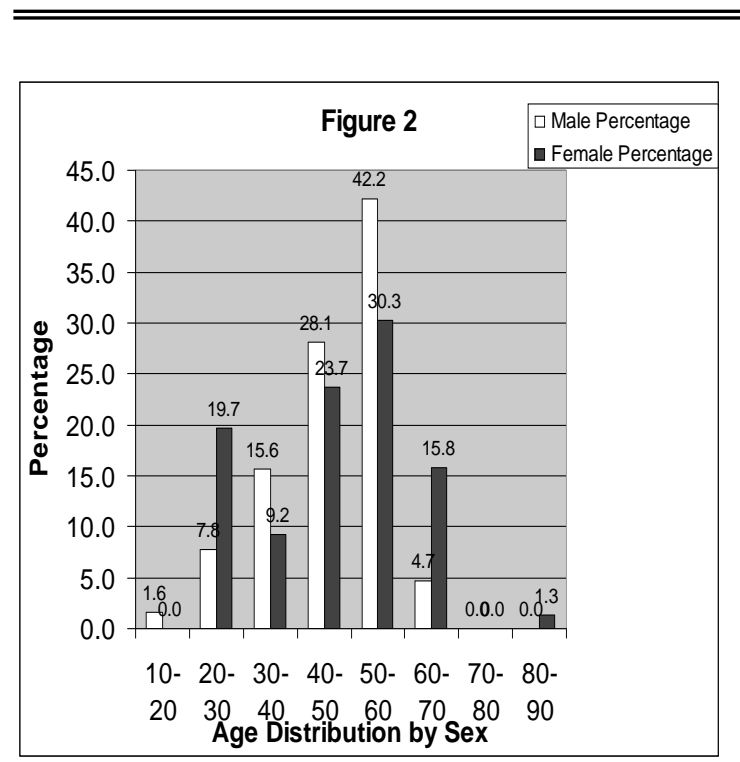

Figure 2

Seventy six male patients (42.2\%) and sixty four female $(30.3 \%)$ out of the 140 total fall into the 50-60 year age range and made up the highest group.

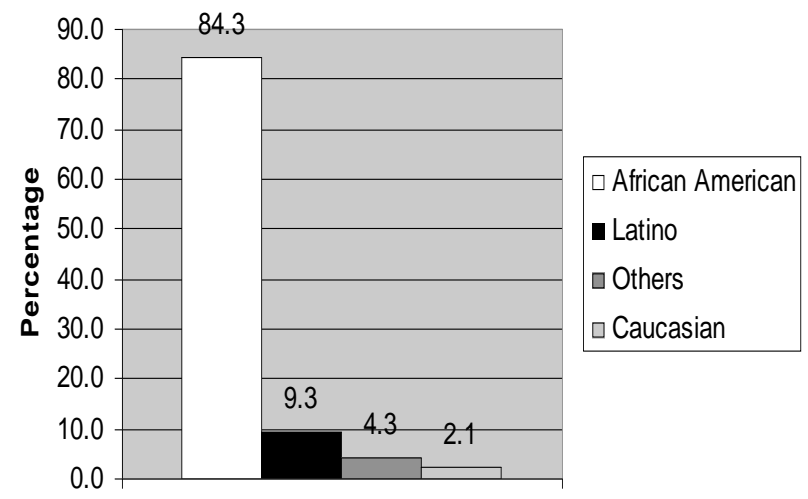

Figure 3

Ethnic Distribution: The African American ethnic group are dominant representing 119 out of 140 or ( $84.3 \%)$ of total, followed by the Latinos at $(13.0 \%)$

Disparities in the health questionnaire responses: Tables 1 and 2 . The result shows that 24 patients did not respond to at least one of the eleven questions, Substance abuse shows the widest disparity with $(12.1 \%)$ responding in the affirmative in the structured oral interview (SOI) compared with $(5.7 \%)$ in the self completed questionnaire. (SCQ) This is followed by HIV/AIDS with $(2.1 \%)$ in the (SCQ) and((5.7\%) in (SOI) and then Hepatitis with $(6.4 \%)$ in the (SCQ) and $(9.3 \%)$ in the (SOI).
Table 1

Self Completed Questionnaire Responses

\begin{tabular}{lll}
\hline Disease & $\underline{\text { No }}$ & $\underline{\text { \% Total }}$ \\
\hline HTN & 37 & 26.4 \\
\hline HIV/AIDS & 3 & 2.1 \\
\hline Blood Disorder & 10 & 7.1 \\
\hline Diabetes & 15 & 10.7 \\
\hline Hepatitis & 9 & 6.4 \\
\hline Substance Abuse & 8 & 5.7 \\
\hline Psychiatric Disorder & 6 & 4.3 \\
\hline Kidney Problem & 3 & 2.1 \\
\hline Respiratory Disease & 17 & 12.1 \\
\hline Cardiovascular Disease & 4 & 2.9 \\
\hline Thyroid Disease & 4 & 2.9 \\
\hline No Response & 24 & 17.1 \\
\hline & 140 & 100 \\
\hline
\end{tabular}

Table 2

Self Completed Questionnaire Responses

\begin{tabular}{lll}
\hline Disease & $\underline{\text { No }}$ & $\underline{\text { \% Total }}$ \\
\hline HTN & 36 & 25.7 \\
\hline HIV/AIDS & 3 & 5.7 \\
\hline Blood Disorder & 12 & 8.6 \\
\hline Diabetes & 18 & 12.9 \\
\hline Hepatitis & 13 & 9.3 \\
\hline Substance Abuse & 17 & 12.1 \\
\hline Psychiatric Disorder & 6 & 4.3 \\
\hline Kidney Problem & 0 & 0.0 \\
\hline Respiratory Disease & 18 & 12.9 \\
\hline Cardiovascular Disease & 8 & 5.7 \\
\hline Thyroid Disease & 4 & 2.9 \\
\hline No Response & 0 & 0.0 \\
\hline & 140 & 100 \\
\hline
\end{tabular}


Table 3 shows that 10 out of 24 patient $(41.6 \%)$ did not respond to at least one question because they did not see it's relevance to dental treatment.

Table 3

Reasons for no response returns

\begin{tabular}{|l|l|l|}
\hline Reason & No & Total \% \\
\hline $\begin{array}{l}\text { Don't know it has correlation to } \\
\text { dental treatment }\end{array}$ & 10 & 41.66 \\
\hline Cannot read well & 6 & 25.00 \\
\hline Don't understand the question & 8 & 33.33 \\
\hline
\end{tabular}

\section{DISCUSSION}

Many of the health history questionnaire in use in many clinics today have not been formally tested for reliability and validity according to Percoraro et al. (1979). There are many authors who have postulated that the self administered health questionnaire alone would make dental treatment suffer, (Abraham-Inpijn et al, 1998) and some believe it is actually beneficial and shows specificity for certain ailments (Sherman et al, 2003). This particular study tends to agree with the premise offered by Fenlon and Macartan, (1999) that the most valid method for assessment of relevant medical history is the structured verbal interview. However, a more comprehensive language sensitive self-completed questionnaire will more than likely improve negative responses.

Some of the patient that were under study did not provide information we sought on the self completed questionnaire simply because they believe there is no relationship between their chief complaint and the dental treatment they are seeking. This will agree with the finding of Fenlon and Macartan, (1999). Lack of functional health literacy may have also contributed to the negative responses that showed up in this study. Julie A. Gazmararian et al. 1(999) have shown that $44 \%$ of adults aged 65 years or older in the USA in fact have low health literacy in a national survey. This may impair elderly patient's understanding of health questionnaire and messages. Looking into the medical history and responses on the questionnaire substance abuse and blood borne diseases particularly HIV/AIDS are relatively under reported. These two show a comparative disparity. It has been reported by some authors that there is disease denial in the black community (Hodge 2001; Leslie, 2006) and this ethnic group constitute $84.3 \%$ of our patients.

It is therefore essential that a dentist should avail himself with the skill to identify the signs and symptoms of HIV/AIDS infected patients and where there are no clinical signs a good history with proper consultation is of the essence. Substance abuse on the other hand creates a number of management issues that include medical problems associated with drug abuse, pain management and behavioral disorders. Some patient will certainly hold out on this information as our data have shown. The lack of or reduction in verbal memory and cognitive performance are some of the signs to look for according to Schits et al. (2007). The reasons adduced by our patients for not responding to a particular question varies. The use of abbreviation in the questionnaire may trigger a negative response if the patient does not have an acceptable health literacy. HTN is one particular word that many are not familiar with in this study.

Conclusion: The combination of a well executed long medical history form along with a balanced structured oral interview are in the best interest of the patient. Cultural differences and social background makes this inevitable. Validity of a self completed health Questionnaire will depend largely on ensuring that it has been formally tested. We concur with those who believe that one method can't be use at the exclusion of the other.

\section{REFERENCES}

Brady WF, Martinoff JT (1980): Validity of health history data collected from dental patient and perception of health status. J Am Dent Association, 101: 64-645.

Scully C, Boyle P (1983): Reliability of a self administered questionnaire for screening for medical problems in dentistry. Commu Dent Oral Epidemiology 1983; 1; 105-108 
Absi EG (1987): A cardiac arrest in the dental chair. Br Dental Journal.; 163: 199-200

McCarthy FM (1987): Malpractice prevention and claims. CDA Journal 1987: 25-27

Percoraro R.E, Inui T.S, Chen M.S, Plorda D.K, Heller J.L (1979): Validity and reliability of self administered health history questionnaire. Public health reports May-June 1979, Vol 94, No $3231-238$.

Abraham-Inpijn L, Smeets E.C, Russel J G, Abraham E.A (1998): Introductory notes regarding a European medical risk related history questionnaire (EMMRH) designed for use in dental practice. Br Dent Journal Volume 185, No 9, pg 445-448.

Sherman W Reeves, James M Tislech, Joanne Katz, Eric B. Bass and Oliver D. Schein (2003): A self administered health questionnaire for the preoperative risk stratification of patients undergoing cataract surgery. Americal J of Opthal, Vol 135, Issue 5, May 2003. pages 599-606.

Felon M, McCartan B (1999): Collecting a verbal history. BDJ Vol 186, No 7, April 10.

Julie A Gazamarian (1999): Health literacy among medicare enrollees in a managed care organization. JAMA, February 10,1999-Vol 281, No 6 pages 545-551

Leslie Fulbright (2006): Disease denial devastating for African-American. San Francisco Chronicle, Monday, June $5^{\text {th }} 2006$

Hodge CE (2001):. HIV/AIDS Impact on the African American Community: Compedium Continuing Edu Dent, 2001, July 22 (3 spec No): 52-56.

Schilt T, de Win MM, Koiter M, Jager G, Kort DJ, van den Brink W, Schmand $B$ (2007): Cognition in novice ectasy users with minimal exposure to other drugs; a prospective cohort study. Gen Psychiatry, 2007 June; 64(6): 728-736. 